\title{
The word reaction: from physics to psychiatry
}

\author{
JEAN STAROBINSKI
}

\author{
(Translated by Judith P. Serafini-Sauli)
}

The editor is grateful for permission to reprint this article, which was first published in Diogenes, no. 93, Spring 1976.

\section{A LATE WORD}

Reagere, reactio does not belong to classical Latin. ${ }^{2}$ None the less, antiquity was not unaware of the concept of reciprocal action, where the 'patient' reacts in return on the agent. ${ }^{3}$ The Aristotelian doctrine of antiperistasis occupied physicists up until the time of Galileo: "All movers, as long as they move, are at the same time moved.'4 The Latin medieval authors dispense with reagere and reactio. It is the verb pati, designating the passive state to which the prefix $r e$ is added in the aphorism attributed to the Scholastics in the eighteenth-century dictionaries: omnis agens agendo repatitur..$^{5}$ In their concern for good Latin, the writers of the Renaissance made an effort to avoid the words reagere and reactio. Vossius allows them a little disdainfully in the study programme of philosophers (in scholis philosophorum) for it is a term proper to the object designated by the two words (vox idonea rei quem signant). But in all other circumstances he prefers expressions such as vicissim agere, resistere agenti in se. ${ }^{6}$

In the philosophical language of the Renaissance, despite the opposition offered by the purists, the term is introduced and becomes widespread. Pomponazzi has written a De

1 Address for correspondence: Professor Jean Starobinski, 12 Rue de Candolle, Geneva, Switzerland.

The term is absent in Souter (1949), A Glossary of Later Latin. It is also absent in Blaise (1954), Dictionnaire latinfrançais des auteurs chrétiens.

s Sir Thomas Heath finds an anticipation of the Newtonian law of the equality of action and reaction even in Aristotle's De Motu Animalium (c. I, 698a). Cf. Heath (1949), Mathematics in Aristotle, pp. 281-282.

- The formula, which is traditional, is here that of Bonamici quoted by Koyré (1939), Etudes galiléennes, vol. I, p. 19.

B Quoted in the article 'reaction' in the Dictionary of Chambers (1743), Dictionnaire de Trévoux, L'Encyclopédie.

- Vossius (1695), De vitiis sermonis, Iv, 20. Quoted as the only example by DuCange (1734), Glossarium ad scriptores mediae et infimae latinitatis, vol. v, article 'reaction'. reactione (published, after his death, in 1525). The De Rebus Naturalibus of Zabarella (1589) contains a Liber de Reactione. In his Lexicon philosophicum (1613) Goclenius gives a definition of reactio which is abstractly extended to all physics: Retributa seu reciprocata patientis actio quaedam qua resistit agenti et id commutat, dum ab eo commutatur.

In the same period (beginning of the seventeenth century) we find the generalized use of the equivalent term in the vernacular languages (French: réagir, reaction; English: to react, reaction; Italian: reattione, etc.). Let us venture a hypothesis here: the term could only acquire all its importance in a cultural climate strongly marked by the Stoic idea of the interdependence of all things in the universe. If all natural beings are equal and interdependent, no action can escape another action in return. The universal law of reaction or retroaction causes the obliteration of the ontological privilege by which an agent is more noble than a patient. All beings are in turn active and passive in their reciprocal relations. And even when the idea $^{8}$ of the qualitative superiority of the active being on the passive being will be upheld, this superiority will be transient (or passing), i.e. communicated from one to another in proportion as the move-

7 Littré however, in his Dictionnaire (1863-77), indicates an older usage which has the notable advantage of revealing the presence of the term in the vocabulary of alchemy:

As fire acts in air,

Thus air reacts on water, And water acts in air

When fire wants to wage war.

This text is at verses $460-467$ of the Complainte de Nature $a$ l'alchimiste errant. The author of this text is most probably the painter Jean Perréal (about 1460). We have been unable to find other examples of the verb réagir (to react) in France before the Physique of Champeynac (1610), quoted by Huguet (1965).

${ }^{8}$ Such as it is affirmed by Thomas Aquinas, from Augustine and Aristotle, in the Summa Theologica, Ia, LxxIX, 2, 3. 
ment spreads. The concept of reaction comes to the aid of the passive object and confers upon him the dignity possessed an instant before by the agent who has made him submit to his 'impression' upon him and who must in turn undergo an 'impression'. There is no fragment of matter in the universe that is not capable of resistance. At the dawn of modern times, no cause (outside of God) is, by essence, superior to another. All preponderance is quantitative: a body exerts more force than another because its mass and velocity are greater. Passivity, for the subject that undergoes, is not the mark of an indelible inferiority; it is a transitory situation in which the energies of the return action are already gathered. Thus the order of nature imposes an identical law for all beings, animate or inanimate. The universe is a homogeneous space in which the slightest alteration, the slightest displacement, 'reacts' on the totality of beings.

In some ways these ideas are common to the Neo-Stoics and to the Peripatetics of the Renaissance and the seventeenth century. They thus prepare the ground for modern mechanics, which will give these intuitions their quantified expression. The article 'reaction' of the Encyclopedie (translated literally from the Cyclopaedia of Chambers, 1743) is very significant in this case. It shows that Newton has formulated, in the language of quantitative equality and in the sole domain of movement of bodies, what had been previously described by means of words in the qualitative phenomena of nature:

The peripatetics defined reaction the impression a body makes on that which has affected it, an impression exercised on the same part of the agent and at the same time that the agent affects it; like water thrown on fire ${ }^{1}$ which extinguishes the fire while it is itself heated... But one did not know that the reaction is always equal to the action. It was $\mathrm{Mr}$. Newton who first observed this.

Thanks to the fame of Newton, the conceptual pair action/reaction acquires undisputed authority in European thought of the eighteenth century. Let us recall his third principle: 'For all action, there is an equal reaction, or: the reciprocal actions of two bodies on each other are always equal and directed in opposite direc-

1 The example of the water and fire is that proposed in 1644 by Sir Kenelm Digby in his Natural Bodies (xvI, 141): 'If fire doth heate water, the water reacteth againe... upon the fire and cooleth it' (as quoted in $O E D$, article react). The example is derived from the medieval tradition. tions' - a notion so famous that it has come to be a metaphoric model in many other domains.

The use of the notion can thus return to being an image and be no more rigorous than it was in the language of the natural philosophies before the mathematicization of their language; none the less, the terms by now bear the sign of the illustrious mathematician. They are covered by a prestigious guarantee. ${ }^{2}$

Even in theological language one evokes the reaction of the soul to the action God exerts on it. That contributed to bring God closer to the creature, as the initiates of Pietism and Methodism hoped:3 God and internal sentiment can meet on the same level, just as an action encounters a reaction. Human love and divine love are forces that can enter into agreement.

It is to Newton, or at least to a Stoic model, that Montesquieu is beholden when he writes: - The parts of a state are like the parts of this universe eternally bound by the action of one and the reaction of the other.' 4 This is not the only example of Montesquieu's use of the lexical pair action/reaction. Each time he applies it to the realm of political matters, he never fails to indicate that he has borrowed it from the vocabulary of physics. Montesquieu does not forget the original register from which he borrows this conceptual tool. The comparison serves him in making it understood that every event and every political decision cause effects which reflect back on the cause of these events or on the authors of these decisions. If one dispassionately examines history, one can never fail to observe the 'just return of things'; each violent movement arouses another no less violent movement which replies to it and sometimes stops it. The play of action and reaction in history ensures inevitable recurrences. In the dynamics of history it represents what the play of weights and counterweights ensures in the

\footnotetext{
- The dictionary of Féraud (1788) makes a state of a mode: reaction, to react 'are used in writings on all sorts of matters'. The beguiling efficacy of the lexical pair action/reaction is never felt more than in the cosmosophic speculations of the end of the eighteenth century and the beginning of the nineteenth century. One need only name Goethe, Schelling, Edgar Poe (Eureka). Edgar Poe's speculation will find a late echo in the Art Poétique of Claudel (1907).

' In 1771 the theologian Wesley evokes 'a continual action of God upon the Soul and a re-action of the Soul upon God' (Works, 1872, vol. v, p. 232). The example is quoted from $O E D$, article 'reaction'.

- Montesquieu (1743), Considérations sur les causes de la grandeur des Romains et de leur décadence, chap. IX.
} 
domain of the statics of institutions. To be more specific: if men do not succeed in preserving political stability by the balance of internal forces in the state, violence will prevail under one form or another; then, by a law as compelling as the laws of physics, the violence exercised by one party or faction will arouse a reaction which will prevent the new power from prevailing permanently. Sooner or later a new balance will be established to be broken once again. In the events that follow, action and reaction come to re-establish violently a balance that men have not been able to establish peaceably by the reciprocal limitation of powers. Montesquieu is convinced that there is always a price to pay for the excess of power: sometimes it is even a high price. For Montesquieu we see the image of action and reaction fill the operative role that we entrust (sometimes with less precision) to the concept of dialectic ${ }^{1}$ or feedback.

\section{REACTION VS. PROGRESS}

The passage of the word reaction into the register of political vocabulary is accompanied by a modification of its value.

We know that Saussure calls the value ${ }^{2}$ of a word the resultant of the relations it maintains in a given moment with all the other words of the language. According to a comparison proposed by the linguist of Geneva, the value of a word resembles that of a chess piece at the moment of a game. It derives from its place in the game, its position in relation to all the other pieces, and the importance given it by pre-existing rules. Among the components of this value, we must add, the greatest attention must be given to terms which enter into an antonymous relation with the word considered. The value of a word in a given language context depends in large part on pairs it can form with opposite terms - be they reciprocal or complementary.

In the language of physical representation, we have seen that the word reaction appeared so as to constitute a pair of reciprocals with action, thus competing with the pair of opposites action/ passion. Action/reaction, in the sense of Newton-

\footnotetext{
1 One grasps the passage from the concept 'of universal reciprocal action' to that of 'dialectic' in its essence in the Anti-Dïhring of Engels (1878) (Introduction, chap. I): 'nature is the testing ground of dialectic'.

'Saussure (1916), Cours de linguistique générale, second part, chap. IV.
}

ian mechanics, constitutes a compensated pair, where the second term only increases the first by affecting it with a prefix (re), one of whose effects is to indicate reciprocity or inverse movement. To be sure, reaction is always second, and even if one supposes it to appear instantaneously, it is a response to an action that has come first. But reaction is not, like passion, the logical or ontological opposite of action; it is another action, equal in dignity, of the same nature, and differs only in its orientation in space.

In the language of politics, qualitative opposition can insinuate itself again in the verbal pair action/reaction. In fact, as soon as the word action receives a laudatory distinction, it becomes inevitable that reaction will in return find itself with a 'negative' and pejorative distinction. From then on it is no longer a complement but an opposite. This transformation is only possible because to convey this new sense, the prefix 're' also acquiesces to signifying backward movement in relation to an action which itself advances in the right direction. The appearance of this new value of the word reaction goes along with the attribution of greater importance to the 'perfecting' which can develop in the course of time. From the end of the eighteenth century, the approval given to a certain type of historic action defined as 'progress' brings with it the meaning of 'conduct hostile to progress' for the word reaction. In a revolutionary period this meaning is all the more imperiously insisted on as the happiness promised is delayed in coming. This delay must be explained and above all a name must be given to the forces, to the ideas and to the men who are accused of being responsible. It is thus that the decade 1790-1800 sees the birth of the pejorative political acceptance of reaction and of the neologisms 'reactor' (used notably by Babeuf to stigmatize the counter-revolutionaries) and 'reactionary' (formed on the model of revolutionary). ${ }^{3}$ In the new conceptual pair action/reaction, which was formed following the French Revolution, the qualitative opposition prevails once again and it is linked to the representation of an antagonism developed in the space-time framework of history. The presupposition of a true sense of history and of a true duty of man is

\footnotetext{
${ }^{3}$ For these new meanings and these derived terms, cf Brunot (1967), Histoire de la langue française, des origines à 1900 , vol. IX, 2, p. 837n, and pp. 843-844.
} 
posed beforehand by virtue of a prefix of direction pro (in progress) and by its opposite re (in reaction). To be sure, the dictionaries of the period defined reaction as the retort of an 'oppressed party that takes vengeance and acts in turn'. Reaction can come from the 'right' as from the 'left' if one believes in this neutral meaning. But very quickly, even in prudent writers, the term reaction designates a return backwards, a 'retrogradation', a destruction of happy changes come about in the State.

In his pamphlet entitled Des réactions politiques (1797) Benjamin Constant writes: 'When a revolution that has been carried beyond its limits stops, one first restores it within its boundaries. But one is not content with restoring it within its boundaries; it is pushed as far backwards as it had advanced forward. Moderation ends and reactions begin.' These new meanings and new linguistic values mark the growing role played from the end of the eighteenth century (and up to our day) by the image of a sociohistorical becoming, bearer of beneficent changes for all of humanity, provided that men rise to the task and fight against those among them who create an obstacle. The stunning success of the scheme action (progress) vs. reaction is due to the fact that it arouses hope and designates an adversary.

\section{VITAL REACTIONS}

If one supposes that the consecration of a medical notion is to be measured by its presence in a dictionary that records it, we must then observe that the word reaction was recognized very late in medical nomenclature. To my knowledge, as far as France is concerned, no medical dictionary mentions the term reaction before the beginning of the nineteenth century. There is no trace of the word in the Lexicon Medicum of B. Castelli (last edition, 1746). The Medical Dictionary of Robert James (for which I have Diderot's translation, 1746-8) does not mention it either. Neither the Cyclopaedia of Chambers (5th edition, 1743) nor the Encyclopédie of Diderot and d'Alembert give it any medical or physiological meaning.

Even if reaction is not yet a concept worthy of being catalogued in a medical lexicon, the naturalists and doctors of that century did not abstain from using the word: it is an explanatory auxiliary which translates the phenomena of life into the language of general physics and of philosophy. Those who have some familiarity with the scientific literature of the eighteenth century know that the lexical pair action/ reaction is often invoked; in fact they have recourse to it every time they want to give the approximate formula of an interdependence and a vital faculty of response. This is true for $J$. T. Needham, ${ }^{1}$ the vitalists of Montpellier, W. Cullen and his pupils of Edinburgh, and D. Diderot in his meditations on life. The pair action/reaction often covers confused intuitions which do not go beyond a pseudo-demonstration of a totally verbal nature.

Of course, the mechanical image of action and reaction was able to lend itself to the still very general statement of what will later be called 'stimulus and response' or 'reflex'. We note that in this first theory of nervous functions reaction is conceived mechanically, without anything intervening to specify the real nature of the biological act with regard to the external stimulant. A sequence is described where the reaction, as a general rule, is proportional to the action; the acting force and the reacting force are held to be homogeneous and of the same nature. Through the detour of chemical analogies they meanwhile begin to move toward the statement that in physiology will be expressed by the law of all-or-nothing. Buffon says nothing unacceptable, but neither does he say anything very rigorous, when he writes in the Discours sur la nature des animaux: 'Objects act on an animal by means of the senses and the animal reacts on objects by his exterior movements; in general, action is the cause and reaction is the effect.' But he goes on:

One might perhaps say at this point that the effect is not at all proportional to the cause; that in solid bodies, which follow the laws of mechanics, the reaction is always equal to the action, but that in animal bodies the external movement or the reaction is incomparably larger than the action... But it is easy to answer... With a spark one sets fire to a gunpowder magazine and makes a fortress explode ... Consequently it should not seem extraordinary that a light impression on the senses can produce a

\footnotetext{
1 For Needham and his reference to the concept of 'action and reaction' see Roger (1963), Les Sciences de la vie dans la pensée française du XVIII ${ }^{\bullet}$ siecle, pp. 504-520.
} 
violent reaction in an animal's body which is manifested by external movements. ${ }^{1}$

Very large use is made of the pair action/reaction at the end of the eighteenth century in all the theories on the relationship of the physical and the mental. The lexical pair act/react permits the description of a double causality, a circle of causes and effects where, once sensitivity has been placed as a general principle, no factor can claim absolute priority or preponderance. From the pen of Cabanis we read these most characteristic of all lines:

One must not...be surprised that the operations which grouped together bear the name of mental, are in relation to those other operations which are more specifically designated by the name of physical, and that they act and react on one another, even if one wanted to consider the various organic functions as determined by two or more different principles...

Organs are only able to enter into action and execute certain movements in so far as they are endowed with life or are sensitive; it is sensitivity that animates them, it is by virtue of its laws that they receive impressions or determine to move. The impressions received by their sentient extremities are transmitted to the centre of reaction; and this partial or general centre sends to the corresponding organ the determinations which all together constitute the proper functions of this organ... Whether these impressions have been received by external or internal sentient extremities, or whether their cause has acted at the seat of the cerebral pulp itself, they always end up in a reaction centre that refiects them as determinations, movements, functions, towards the parts to which each of these operations is attributed. This action and reaction can often take place without the individual being aware of it. ${ }^{2}$

The area thus covered by the notion of action and reaction is remarkably vast. As we have just seen, it includes the unperceived phenomena of the autonomic nervous system, the subconscious of organic life. It covers the whole domain of responses that the 'reaction centres' bring to the perceptible stimulations coming from the outside world or internal organs. It is also applied both to the incitements emitted by the 'cerebral pulp' and to those produced at the level of the organs

\footnotetext{
1 Buffon (1836), Oeuvres completes, vol. IV, pp. 364-365. For the role of the image of explosion in the formation of the notion of reflex of. Canguilhem (1955), La formation du concept de réflexe.

- Cabanis (1802), Rapports du physique et du moral de l'homme, onzième mémoire, chap. $\mathrm{I}$.
}

themselves. Let us underline here the use of the verb reflect, used doubtless by virtue of the prefix re which brings it close to react. In the work of Cabanis reflect is a multivalent term which designates by turns the return of a force in movement (here, sensation) to its source reffected attention, motor reflex (the interdependence of the physical and the mental), etc. Cabanis often refers to 'analysis'; but in resorting to the concept of action and reaction, or to that of reflected movement, he employs a ubiquitous metaphor which dispenses him from pushing his analyses beyond a certain point, because these terms lead to believe that the analysis has been pushed back to the elementary base. It will be up to the following generation to dismember the too vast territory of reaction so as to isolate, with narrower but more specific concepts, the types of phenomena best suited to experimental investigation.

Around 1820 there are many who state that the concept of reaction has received such broad acceptance that it becomes applicable to all phenomena of life. ${ }^{3}$ Now in the domain of sciences, too broad a concept is no longer functional.

The concept of action/reaction was taken from mechanics and does not authorize the establishment of a difference in nature between the acting force and the reacting force. The cerebral 'centre of reaction' is the place where sensation is modified into 'ideas', 'volition', 'attention'; all that reflows or is reflected towards the periphery at the level of the centre, is always nothing but sensation. The same energy develops in the two directions - centripetal and centrifugal: 'Sensation, which at first seems to have flowed from the circumference to the centre, returns later from the centre to the circumference, and ... in a word, the nerves exert a veritable reaction on themselves regarding feeling, just as they exercise another reaction on the

\footnotetext{
3 'Life is a series of impressions received and reactions performed by the different sensitive centres', writes Delpit (1820) in the article 'reaction' of the Dictionnaire des Sciences Médicales. 'Just as we live ceaselessly under the influence of physical stimulations and mental affections, it follows that outside the time of sleep, we live under the rule of continual reaction', states Bricheteau (1827) in the article 'reaction' of the Encyclopédie Méthodique (Médecine) vol. xul. Later on, in 1874 , Bernheim recognizes that 'the word reaction has taken on such a large sense ... that is can no longer be defined, that it no longer bears a precise meaning' (article 'reaction' of the Dictionnaire Encyclopédique des Sciences Médicales, 3rd series, vol. II).
} 
muscular parts for movement.' The pair action/ reaction, in its mechanical meaning of reciprocal action, does not prefer any of its constituent terms; it constitutes the model of functioning required by a materialist and monistic system, which intends to dispense with the Cartesian hypothesis of a non-material, free, self-willed soul. ${ }^{1}$ The idea of reaction therefore covers a highly polemic idea, since it is proposed as an explanatory principle, in place of the 'thinking substance'. Thought itself is nothing but a reaction among many. ${ }^{2}$

However, if the idea of reaction met with brilliant success at the beginning of the nineteenth century, it is not in the meaning Cabanis gives it, but rather in the sense that the vitalist theory confers upon it. The vitalists held to the idea of a 'vital principle', irreducible to sole physico-chemical phenomena. Now the characteristic of the 'vital principle' is to harmonize the various functions of the organism and to defend it against the blows of harmful agents.

It is here that the concept of reaction intervenes in a new sense: it is the original response that the organism opposes, under the direction of the 'vital principle', to all that endangers its survival. When the word reaction made its entrance into medical dictionaries at the beginning of the nineteenth century, it was given a strictly vitalist significance. Here is the definition given by Capuron:

A kind of movement which tends to prevent or destroy the effects of all harmful powers applied to the animal organism and that certain doctors have attributed to what they call the medicating force

\footnotetext{
1 Cabanis (1802), Rapports du physique et du moral de l'homme, deuxieme mémoire, Histoire physiologique des sensations, paragraph vi. A few lines later Cabanis goes on to say that sensibility acts like a fluid whose total quantity is determined and which, every time it casts itself in greater abundance in one of its channels, diminishes proportionately in the others'. On the role of this metaphor in the history of psychiatric thought and on the image Freud makes of it cf. our study 'Sur les fluides imaginaires', in La relation critique, Paris, 1970, pp. 196-213.

2 This will be affirmed later by empiricists like Mach (1902), Die Analyse der Empfindungen, pp. 245-246. In the Cahiers of Paul Valéry (1973), we find the peremptory affirmation: "The notions of thought, knowledge, etc. must be discarded. Those of act and reaction must replace them (I, 954). The psychology of Jean Piaget, which insists on action, assimilation and accommodation seems aimed entirely at resuming and surpassing, in a decidedly active sense, all that the long dominant concept of reaction led to believe about the necessary link between the individual and the surrounding world: knowledge is a constructed response.
}

of nature, vegetable principle, soul, organism etc. $^{3}$

The essential idea is thus that of resistance (one will note the reappearance of the prefix $r e$ ) whose secret belongs to living beings and to them alone. There exists, therefore, a kind of reaction that is the privilege of life and, even more, is the very definition of life. The opening lines of the famous book of Xavier Bichat should be recalled here:

One seeks the definition of life in abstract considerations: it will be found, I believe, in this general insight: life is that group of functions which resist death. The mode of existence of living bodies is such in effect, that all which surrounds them tends to destroy them. Inorganic bodies act incessantly on them; they themselves exert continuous action on each other; they would soon succumb if they did not have a permanent principle of reaction within them; this is the principle of life; unknown in its nature it cannot be appreciated except by its phenomena. Now, the most general of these phenomena is this habitual alternative of action on the part of exterior bodies and of reaction on the part of living bodies; an alternative whose proportions vary depending on the age.

There is a superabundance of life in a child because reaction exceeds action. The adult sees an equilibrium develop between the two, and because of that, this vital excess disappears. The reaction of the internal principle diminishes in the old man, while the action of external bodies remains the same; then life languishes and goes imperceptibly towards its natural end, which arrives when all proportion ceases.

The measure of life is therefore, in general, the difference that exists between the effort of external forces and that of internal resistance. The excess of the former announces its weakness; the predominance of the latter is the sign of its strength. ${ }^{4}$

We meet here with an agonistic definition of life: life only exists as long as it can pursue the struggle against the hostility of the non-living world. If to live is to react, one is tempted to consider all reaction, of whatever nature it may be, as a healthy effort of the organism. There can

\footnotetext{
${ }^{3}$ Capuron (1806), Nouveau dictionnaire de médecine, de chirurgie, de physique. Capuron's definition is repeated unchanged by Hanin (1811), Vocabulaire médical, and again in the first edition of Nysten (1814), Dictionnaire de médecine. For the spiritualism of Capuron (a former Oratorian) and the vitalism of Nysten (disciple of Bichat), cf. Florkin (1954), Médecine et médecins au pays de Lidge, pp. 169-190.

- Bichat (1800), Recherches physiologiques sur la vie et la mort, first part, article 1 .
} 
be nothing but good reactions. And just as Hippocratic medicine tended to favour 'the medicinal force of nature', vitalist medicine wants to be nothing more than the art of provoking or favouring reaction, to the point that one can count on the presence of the principle of resistance. Should a fever arise, one will see in it the indication, favourable in itself, of a mobilization of defensive energies. ${ }^{1}$

It is difficult to preserve such a general principle pure and undivided. After having identified reaction and life, Bichat feels the need of subdivisions: animal life and organic life are to be differentiated. And the notion of reaction, so important at first, becomes slightly blurred in the rest of the work. By its very generality the concept is not easily manageable; by itself it does not permit the definition of the various functions.

The authors who spoke of reaction around 1820 proceeded in turn to some distinctions. In this regard the articles of medical encyclopedias are of great interest. Delpit ${ }^{2}$ separates physical and mental reaction. What is physical reaction? It is the defensive energy mentioned by Bichat: it 'acts against all causes of destruction, derives its means in the more or less constituted elements of the structure and is found essentially bound to the vital properties which, by presiding over all functions, direct the acts of preservation of the individual or the species'. But physical reaction consists also in the 'uninterrupted circle of reciprocal influences' which links the operations or functions of the different organs among themselves. Can one assert that reaction always infallibly assures the defence of the individual? Do we not observe the occurrence of harmful reactions? Delpit, who does not exert himself to respect vitalist orthodoxy, makes a point of

\footnotetext{
1 For another physiologist fifty years later the concept of reaction intervenes once again in a fundamental definition. But for Moritz Schiff, it is no longer a question of defining life in general: it is a question of the speciality of animal life. And reaction is no longer conceived as a response to an external environment; it establishes the solidarity of the parts. 'There exists ... in the animal a reciprocal reaction of all the parts in which one can respond to the irritation of the other. This reciprocal unity gives the animal a kind of individuality that is lacking in plants.' Schiff (1894). Recueils des mémoires physiologiques. I, p. 464.

'Delpit (1820), Dictionnaire des sciences médicales, vol. 47 , article 'réaction'. This physician, doctor at the University of Montpellier, was the friend of Maine De Biran with whom he founded the Medical Society of Bergerac in 1806. Cf. Biran (1954), Journal.
}

aberrant reactions against which medicine must intervene.

This physical reaction cannot constantly be determined by conservative views, nor can it always be confined within convenient limits. Thus the reaction of the organs of generation, when too strongly exercised by the impression of stimulating substances, can reflect on the cerebral organ and determine all the phenomena of sexual neuroses. The reaction of the blood system against obstacles placed in the way of circulation by defective formation or a momentary disturbance of the organs, can determine the rupture of the vessels or an equally dangerous outpouring of blood. Therefore the physical reaction of organs has its aberrations and its excesses; to be beneficial it must remain under the influence of careful medical care and with this help create a barrier against harmful deviations.

In Delpit's view then, the reassuring teleology of reaction allows some exceptions: in these cases therapeutic measures must come to the rescue. Without going so far as to dispute the generally favourable nature of physical reactions, Delpit admits that on certain occasions they exceed limits and must be contained. It is what Bricheteau, in another publication, ${ }^{3}$ calls "pathological reaction'. Nevertheless, it is there that therapeutic intervention finds its model: in arousing a new reaction, a counter-reaction, one can stop pathological phenomena:

Let an organ like the stomach or the brain, etc. be seriously injured, upset in its parts; aside from the local injury, as a result of a strong reaction, mishaps occur in a multitude of other organs: a fever develops, there is difficulty in breathing, trouble in the functioning of the liver, the kidneys, the intestinal tract, etc. Would you like to use this reaction to the advantage of the entire organism? Administer an emetic whose action will affect the brain, or else apply mustard plasters to the feet, so as to obtain the same result.

The multiplied sympathies of organs sometimes yield to double reactions or reflected reactions...

We can see that the concept of reaction is allowed to be used in all senses. It dispenses with adducing a pathenogenic mechanism or a mode of action which might be specific or subtle. It assures the appearance of an explanation without

3 Bricheteau (1827), Encyclopédie Méthodique, Médecine, vol. XII, article 'reaction'. Isidore Bricheteau (1789-1861) was doctor at the Necker hospital and member of the Academy of Medicine. 
having recourse to a cause or to means any more specific than those designated by the all-purpose word of that same period, 'sympathy'.

\section{MENTAL REACTION}

The dichotomy of the 'mental' and the "physical' offers an ideal pair for the comings and goings of action and reaction. If an organ is irritated it will react on the brain. The troubles of the spirit of somatic origin will be described as the effects of a reaction. Delpit does nothing more than transcribe some very old affirmations, well formulated by Galen, into a renewed language. Here the word reaction modernizes the traditional statement:

The exercise of physical reaction is not limited to the systems or to the organs of which our body is composed; in certain cases we see it affect the mind as well. Any alteration of an organ reacts with vehemence on the faculties of the spirit or the affections of the soul. Thus the stomach, excited by wine or other liquors, reacts on the mind which at that point becomes more lively, sharper and more ready with witty remarks. Swelling of the liver and of the spleen bring sadness, discouragement, melancholy, etc. ${ }^{2}$

It goes without saying that the opposite is also considered true and that 'the mental is able to act on the physical'. Thus can Bricheteau write:

As with the organs, the body and mind of man, considered abstractly, act on one another. A man taken ill, will have difficulty recovering if he is dominated by sad feelings and bitter grief; in the same manner it is unlikely that an ailing man can use his faculties with success. In the first case, eliminate the mental ailment and you will react on the illness; in the second, make the suffering cease and you will reestablish the free exercise of the intellectual faculties. This means that physical forces can be immediately debilitated or re-established by the influence of a great and deep impression. Joy and terror can bring death, just as great excitement of another nature seems to mend the fabric of life or resuscitate the exercise of functions that seemed permanently

1 Among historians the term has led to confusion. There is a great difference to be established between cosmic sympathies, postulated by the paracelsian doctors of the sixteenth and seventeenth centuries and physiological sympathies for which the theory was developed in the eighteenth century by the school of Montpellier and especially by P. J. Barthez. It could be demonstrated that the system of sympathy developed concurrently with the system of reaction and that both were supplanted at the same time by the recognition of reflex movements.

2 Delpit (1820), Dictionnaire des sciences médicales, vol. 47, article 'réaction'. destroyed. A mountaineer far from his native land falls victim to nostalgia, loses his strength and can barely take a few steps in a hospital which seems destined to be his tomb. Give him hope of seeing his mountains again and all is changed. He recovers his strength, his appetite and the use of his legs. Do you want to react on the mental state of an unhappy man who is being secretly undermined by a deep grief caused by reverses of fortune? Instead of giving him drugs, imitate, if you can, the great practictioner of the last century who after having unsuccessfully treated a businessman in difficulty with his business, cured him almost immediately by giving him a prescription of thirty thousand francs to be filled by his notary. ${ }^{3}$

We must distinguish in this text between the affirmation of principle and the illustrative examples. In principle there is nothing against a reactive theory of physical alterations due to passions and to disorders of the mind. The notion of reaction can be perfectly applied to what we call today - with a controversial term the psychogenesis ${ }^{4}$ of somatic ailments or mental illnesses.

Bricheteau, on the other hand, scarcely dwells on this. Does the idea of the mental cause of a great number of physical ailments and mental disorders seem to be self evident? It was certainly common currency, and perhaps it seemed so unquestionable that nothing indicated the need for calling upon the concept of reaction on its behalf.

A mountaineer far from home is a potential victim for nostalgia: financial troubles secretly undermine the health of a businessman unhappy about business; this is considered undebatable evidence according to the tradition of a psychosomatic doctrine already perfectly formulated by Stoic philosophy and by Galen. To express the pathogenic role of an idea or a passion it is the concept of influence which is most frequently utilized. Everything takes place as if one preferred to keep the concept of reaction in reserve. Why? For what purpose? To give it a very particular role in the mechanism of spontaneous or induced recovery. The word thus designates a promise of healing that the doctor hopes to encourage or arouse. Here at the level of

\footnotetext{
S Bricheteau (1827), Encyclopédie méthodique, médecine, vol. XII, article 'réaction'.

- Cf. Lewis (1972), 'Psychogenic': a word and its mutations.
} 
psychotherapy, the concept of reaction again takes on the defensive value that Bichat had given it in the general order of vital faculties.

In the examples proposed by Bricheteau a supplementary notion comes to connote reaction: it is abruptness, the sudden effect. From that point, reaction appears as an instantaneous event; it achieves a brusque overturning; it resuscitates. Mental ailment is to be cured, or organic troubles caused by passion are to be relieved, by producing an idea or emotion which will unleash the good reaction in a single stroke. For a long time doctors had imagined mental disturbance under the almost literal aspect of the breakdown of a machine. What resource should be used to recover the harmonious arrangement of faculties? First of all, a shock: physical shock (cold, a blow, whirling) and mental shock (fright, surprise, joy, etc.). One expected an effect similar to that of a magic wand or more simply like the jolt that sets a stopped watch working. What better scientific name to give it then, if not that of reaction?

All the naive staging set up by the old medicine of the spirit and by the psychiatry of the nineteenth century find their justification in the hope of arousing the decisive reaction. A phantasm of immediate recovery thus comes to inhabit the concept of reaction. To react is a phasic phenomenon whose effects always manifest themselves immediately. Thus the word reaction takes on here a strong antonymous charge: it is not only the contrary of some action come before which has endangered organic or psychic integrity. It implies a marvellous rapidity which is opposed to all that is secret, slow, chronic, in the process of illness. In the admirable Adieu of Balzac, when he reconstructs the scene of the battle of Beresina around the mad young countess, it is to make her re-live the initial moment of her madness, after years of illness, and to induce a kind of instantaneous curative reaction. This latter does not fail to occur, but with such violence that the young woman, once given consciousness, cannot bear it and dies immediately.

But Balzac, who nevertheless knows the medical vocabulary well, does not speak expressly of 'reaction'. What he mentions in his story is the sudden return of will in a being who had been abandoned by that faculty: "Human will came with its electric flow and revived this body from which it had been absent so long." Balzac has not strayed for all this from the doctrine of reaction such as it was formulated in 1820 . In this doctrine the restitution of voluntary energy is the final result of mental reaction. This for Delpit is the complete achievement: 'The mental reaction has its source in courage, in this strong determination of the soul which raises itself above all pains, masters all impressions and substitutes for them acts of will.'?

The mental reaction can thence be defined as the act of courage that yields will; it is the event by which the individual is brought back to the possibility of being newly active and free. Reaction takes on such a positive value, so charged with combative energy that it becomes a veritable action. But have we not come full circle? From the moment one supposes that the source of reaction is courage has one not lost the match? As in all moralizing theories of psychological recovery, does one not assume precisely the faculty that is lacking and that must be recovered? For it is by a simple verbal artifice that Delpit distinguishes between the source of reaction (courage) and its effects (the acts of will that substitute 'impressions' of pain). It must be admitted that in many circumstances discouragement, and as a consequence the impossibility of reaction, prevails. The alleged 'source' dries up. Delpit does not formulate this objection but he anticipates it. If courage fails the patient, it should not fail the doctor, and thence all is saved: the reaction will take place. By now the game is played in the "doctor-patient relation'.

The doctrine of mental reaction, for today's reader, has all its interest in the role it makes the doctor play. Between the Hippocratic tradition (which insists on the virtues necessary for a doctor: serenity, temperance, kindness) ${ }^{3}$ and contemporary psychosomatic medicine, which invites the consideration of transfer and the function of the 'doctor as a drug' (Balint), one must not fail to notice the reflection that

\footnotetext{
1 Balzac (1966), Adieu, in La comédie humaine, l'Intégrale, vol. vII, p. 58. The principal text of Balzac is Louis Lambert: the theory of will as it is developed by the hero of this novel is a doctrine of action and reaction. We have devoted more thorough attention to this in Starobinski (1975), La vie et les aventures du mot 'réaction'.

Delpit (1820), Dictionnaire des sciences médicales.

s Cf. in particular the treatise $D u$ Médecin and $D e$ la Bienséance. These two treaties are found in vol. Ix of the Littré edition.
} 
develops in the romantic age around the concept of reaction. It is an essential link. The figure of the doctor finds itself invested with a greater authority and social role. A myth is constructed that surrounds the doctor with an aura of power, and it is not incorrect to see in this the beginning of a new prestige attached to the medical profession which had been relatively discredited up to the end of the eighteenth century. Particularly evident is a special attention, still a bit vague and pompous, devoted to the personal influence of the therapist. As we know, this interest will become more particularly explicit in the following decades of the nineteenth century at the time of the debates on hypnosis, suggestion and hysteria: psychoanalysis is born in their extension.

In 1820 , when the doctrine of mental reaction is pronounced, the doctor appears as a possessor of energy and courage. By a sort of contagion or fluidic influence, he is capable of infusing the patient with the mental resource of reaction. Delpit avoids all allusion to animal magnestism, but others will be less reserved. As soon as will and courage are represented as communicable substances, there is a great temptation to take the image literally and to imagine a kind of energetic 'transfusion' between the doctor and the patient. We will cite a characteristic page of Delpit. We can measure how far from it we are, but in what he says of the assistance the doctor offers in a healing reaction, we will observe that he did not fail to recognize the feelings of the patient (his need to pour out his soul, his need to be loved) nor the conditions of transfer (prefigured here by the more mild term of 'confidence').

Not all illnesses have as their basis the alteration of organs or the disorder of their functions; also, not all diseases respond to cathartics, narcotics, tonics or blood lettings. The doctor, who is obliged to offer resistance to the sad ravages of boredom, of ambition, of grief, of love, needs a different medical background than that formed by potions and pills. When courage is demolished by reverses of fortune, the torment of passion, a deep feeling of great grief, the fear of a pressing danger, can the good doctor resort only to a material therapy? Will he not have to rise to the hidden springs which move our passions, which can develop the courage of the spirit, the source of so many heroic acts and such marvellous cures? Will he not, in certain cases, have to give a direction to certain impressions of the soul which might then react with success on physical impressions and modify them completely?...

Joy, hope, all sweet and agreeable sentiments fortify the soul and give it the means to react with success on muscular forces and on organs which perform vital functions. All that elevates the soul strengthens the body, said Seneca; but what sentiment can raise the afflicted soul of one crushed by pain, consumed by illness, one whose structure is threatened by complete dissolution? Where will he derive the courage necessary to react on the material causes of destruction, to stop or suspend its progress? $\mathrm{Oh}$, if a means is still left to revive the hopes that each instant seems to destroy, this means will be found only in the confidence inspired by the doctor. How powerful this source is when handled by an able hand. How many storms aroused by mental emotions are calmed by the voice of the doctor, whose duty is mixed here with that of the most delicate friendship. The unhappy patient needs to pour forth his soul: who better than the doctor is used to lending an attentive ear to the long list of afflictions. Also, the patient has hope in him and this confidence is already a restorative balm, a gentle stimulant to the whole organism. In turn the doctor must neglect no means of inspiring or fortifying this confidence since it can so happily reinforce the action of the medication and so effectively help the reaction of the mind on the body. Calm and serene air, affectionate care, language that is easy to understand, promises stripped of exaggeration, foreign luminaries called for consultation, speech in which science discards all that is obscure and severe, where language borrows the expression of the heart and interest, all this in the manner, the words, the actions of the doctor must help to strengthen this confidence, which contains a powerful means of arousing the entire being and of preparing favourable solutions to the ailment.

Further on Delpit adds: 'More than anything else men need to be loved, and this sentiment is sweeter and more paternal for them when it is offered by those whom they have already entrusted with the care of their lives.'1

In the meaning that is specified here, reaction is a curative process which is accomplished thanks to the psychic energy of the doctor. The therapist is considered the master of reactions; if he is intelligent he will know how to choose words, gestures, at times even physical means, which infallibly determine the awakening of the mental forces of the patient and the victory over his illness. He is a fighter who communicates his

\footnotetext{
1 Delpit (1820), Dictionnaire des sciences médicales, vol. 47, article 'réaction'.
} 
vigour; he gives the 'patient' the faculty to become once again a voluntary 'agent'; he frees him from the servitude of 'passion'. Now, the ideal image of this liberation (as of all liberation - our political myths are proof of this) makes it happen in a 'rapid' illumination where suddenly courage, conscience and sanctity triumph. The immediate effect attributed to reaction will permit explaining 'naturally' that which popular belief retained a miracle. Once the figure of the doctor has become that of the 'lay saint' how can it help but inherit healing powers which belonged to ancient religious figures?

It is highly significant to see Hippolyte Bernheim, in the article of the Dictionnaire Dechambre (1874) draw our attention to the effects experienced from emotion and on the sudden healings of nervous ailments. The interest is in hysteria:

The doctor ... threatens a woman who has hysteric convulsions with showering or actual cautery and succeeds with this intimidation, in certain cases, in preventing the return of attacks. He stops the epidemics of hysterical convulsions, of demonomania, by suppressing the mental causes that have produced them and by impressing other emotions on brains excited by unhealthy passions. Some nervous ailments in which the brain seems to take no part can be cured rapidly under the influence of a strong emotion, even when they have resisted all therapeutic agents...The hysterical contraction of limbs, after having resisted all medication for months and years, and when the medulla was believed sclerotic, could sometimes recover immediately under the influence of an event that strongly strikes the imagination. ${ }^{1}$

Bernheim calls Laycock and Charcot to witness and quotes them at length. Like them he appeals to these cures to combat 'the supernatural in therapeutics' and the belief in miracles as manifested in the cult of relics or pilgrimages to Lourdes. At the time of this article Bernheim makes no mention of 'suggestion' of which, at Nancy, he was to become an assiduous experimenter and theoretician. ${ }^{2}$ In the doctrine he will elaborate, suggestion will become the effective agent of all instantaneous healing. At that point the concept of reaction can pass to the second

\footnotetext{
1 Article 'réaction' of Bernheim (1874), Dictionnaire encyclopédique des sciences médicales, vol. 2.

- On his role on the scope of modern psychiatry, cf. Ellenberger (1970), Discovery of the Unconscious, pp. 85-89 et passim.
}

state ... Vitalist teleology seemed untenable to Bernheim:

Those who would seriously like to admit a vital principle stand guard over the organism like a vigil sentinel which discards all that is harmful; those who actually admit that all reaction is a healing effect of this vital principle make the best of a primitive doctrine going back to the infancy of our science, and revolt against all the progress of modern anatomy, physiology and biology.

Of course there are 'adapted reflex movements', but 'is it necessary to invoke the existence of a special principle in charge of our defence?'. Not at all. Biological laws obey their own necessity: 'Bound to the properties and structure of our tissues, reaction is produced without knowing if it will be useful, harmful or indifferent to the organism .... the history of reactions is all of pathology.' If everything is reaction in pathology, everything concerns reaction in therapeutics: "To provoke or encourage useful reactions, to prevent or combat those that are dangerous, that is the whole role of the doctor ... The whole art of healing is in the science of reactions.' 'Reaction' as an all-purpose concept covers too many phenomena to designate each of them with sufficient precision. By saying too much, this word says nothing. ${ }^{3}$ Only 'mental reaction' - a particular case in the psychoneurological domain - is delineated with greater clarity. Must one renounce recourse to this term?

In fact, it was destined to recover a new pertinence but in an entirely different, more determined and more limited meaning. At the -same time that the concept dissolves because it can be evoked everywhere and at all levels - in the regulations which maintain the constancy of the internal environment, in the adaptation to the external environment, in each response following a stimulus observable by the psychologist - one reserves the need for a term which, among the etiologies of diseases, defines in general those where neither an organic lesion, nor the direct effect of an infection, nor an

3 For Bernard (1865) 'the most superficial examination of all that happens around us shows us that all natural phenomena come from the reactions of bodies upon each other' (Introduction à l'Etude de la Médecine expérimentale, II, I, VII). Research will only become exact when it will apply itself to intercepting the determinism that governs 'the reciprocal and simultaneous reactions of the internal environment on the organs and of the organs on the internal environment' (II, II, 3). 
anomaly of functions due strictly to constitution, are present. From then on the tendency will be to reserve the use of 'reaction' and 'reactional' to designate a particular type of causality of illness: all ailment that can be assimilated to behaviour aroused by an external event is reactional.

The appearance of the adjective 'reactional' in the French language dates back to 1869 . Littré, who includes this word in his Dictionnaire, marks it as a neologism and defines it broadly: "That which relates to an organic reaction. The reactional power of an organ against a disease bearing action.' But as general as the definition may be, one must not be content with seeing the persistence of the vitalist tradition in this term; it is called into existence as much by the need to thwart organicist imperialism, which had long prevailed in the course of the century. The interpretation by lesion, inflammation and neoformation would have to have triumphed, anatomical documents in hand, for the class of ailments sine materia to be defined, regrouped, and qualified by 'functional' and 'reactional', where one could incriminate the failures of the regulating mechanisms. This concept of 'reactional' is still the one we use today.

\section{PSYCHOPATHOLOGY OF REACTION}

It will suffice that the notion of 'traumatism' renews the image - this time in the psychological order - of a harmful external intervention for the idea of reaction to regain all its validity. There is no lesion that is not followed by an effort at recovery - rehabilitating, repairing, reacting: words linked by the same prefix of return activity and which are imposed indistinctly. When in the word 'abreaction' Freud and Breuer add a supplementary prefix, they perfect a scheme of opposition that urges an imaginary representation, at the same time dynamic and material. ${ }^{1}$ While traumatism strikes the subject from 'without', the abreaction is a movement that departs from 'within'. If the word traumatism evokes the image of a wound caused by a hard object, abreaction is described so as to make us imagine the 'fluid' substance of emotion drained towards the outside-liquidated. Thus the pair 'traumatism-abreaction'

1 Studien über Hysterie (1895). constitutes a pair of notions that are symmetric, inverse, correlative.

We must go further. The abreaction is not only defined in relation to traumatism but is defined as one of the two opposite forms of the response to traumatism. On the level of reactive behaviour itself the 'abreaction' is the opposite of 'retention' (or of 'repression, of the affective stasis). The opposition between 'liquidated 'emotion and 'non-liquidated' effect is considered radical: it is the criterion which allows us to decide between normal and pathological reaction. Here the reinforcement of the antonymous function is considerable. The abreaction is coupled with 'traumatism' which it follows; but at the same time it represents, for the subject, a 'choice' opposed to that of 'retention', which generates hysterical symptoms. Retention is given the name 'reactional illness' since complete $a b-$ reaction is the normal process.

Lastly, 'the reactional illness' is defined ( $a$ ) as a response to a traumatism, and more generally to an action exercised from without; $(b)$ as what prevails in case of failure or insufficiency of the abreaction. On the lexical level we are here in the presence of strongly marked 'values' organized according to a scheme simple enough to impose itself rapidly and differentiated enough (since there is double discrimination) to welcome a subtle casuistry.

Another observation must be made: the clarity of the scheme we have just set out depends on the punctual, unique and singularized nature attributed to the traumatism. In order to draw the paths of reaction in such a precise manner one must correlatively specify the event that provokes it and give it an isolated, circumscribed existence limited in time. Though in return this event might lose the kind of privilege that makes it stand out among all experiences, though it may dissolve and become fluid to include the social milieu, circumstances, etc., the reaction is no longer expected to respect the alternative of the liquidation or the non-liquidation of an emotion. The more the acceptance given to the instigating circumstance is extended, the more the list of possible variants of the reaction will in turn be extended. This list, as established by Jaspers, ${ }^{2}$ goes from prison psychosis to nostalgia and psychoses due to deafness. It is enough for us to

\footnotetext{
2 Jaspers (1948), Allgemeine Psychopathologie, second part, chap. II, sect. II, I, pp. 319-327.
} 
establish a strict temporal relationship between a provoking circumstance and a reactive state; it is enough for us to establish a comprehensible relationship (ein verständlicher Zusammenhang) between an experience lived and subsequent pathological behaviour.

Does not the concept of reaction become too broad once again? One might have this fear. But it retains its operational usefulness in the language of psychiatry from the fact that it remains linked to a system of conceptual oppositions. It is found mingled in with antonymous pairs, 'endogen/exogen', 'organic/functional', 'somatogenic/psychogenic'. 1 None the less, we are only too aware that these pairs of concepts are far from being interchangeable; they can only be partially superposed. Reaction is neither a completely exogenic phenomenon, nor entirely a functional production... The notion of reaction cannot be reabsorbed in one of the pairs we have just mentioned. It retains its own legitimacy in the vocabulary of theory because it involves still another value of opposition on the level of the very conception of illness. It is in fact opposed to a classifying nosology which takes inventory in a determining way of the genera morborum, and according to which all patients virtually bear their diagnosis within them, from the fact of the precise category of illness into which they fall. Attention to the individual experience is required each time for the ever new response to an ever new situation. Adolf Meyer was thus able to give the notion of reaction a polemic and critical value; he hoped to loosen the hold of the old psychology of faculties, escape from a pseudo-physiology that fancifully invoked the 'elements' of psychic life. He demonstrated the totally arbitrary nature of compartmentalization imposed by a nosology that described mental ailments as invariable essences. $^{2}$ This happened at the beginning of our century and this plea for a psychiatry of reactions itself aroused critical responses.

Once the notion of reaction and reactional ailment is granted against other etiological hypotheses, the role of interpretation is still considerable, and the temptation of antinomies

\footnotetext{
1 Cf. Lewis (1971), 'Endogenous' and 'Exogenous': a useful dichotomy?

- The principal articles of Adolf Meyer have been collected in Lief (1948), The Commonsense Psychiatry of Dr Adolf Meyer. See in particular pp. 193-206.
}

one last time returns to manifest itself with force. However sincere the desire may be in each case to determine equitably the share of the subject and the share of circumstance, it is difficult not to burden one or the other, to impute to one or the other a 'fatal error'. At one of the extremes of interpretation the subject is put on trial: he 'performs' his sickly reaction with all his being. One can allege his constitutional deficiencies, one will say he did not know how to dominate the circumstance, that he has reacted 'in short circuit', that he has involved himself in an aberrational 'perlaboration'. At the other extreme the notion of reaction leads to incriminate the environment, society, even the economic system to which the subject is unwillingly submitted. From then on reaction is no longer interpreted as a loss of mastery but as the only response possible in an intolerable situation. (And one does not wonder why, despite everything, psychotic reactions are so exceptional that revolt itself can remain compatible with the criteria of psychiatric normality. $)^{3}$

In the psychological sense reaction is lived as an event; it is the dramatic confrontation of an individual and a surrounding reality. The link between the two 'actors' is evident. Now if he likes, the interpreter can indefinitely play one of the terms against the other; or, at the very least, through accusatory thinking, which enjoys establishing responsibilities, can designate the guilty. But the task of true criticism is to avoid the easy satisfactions of accusatory thinking such as it is notably expressed in the most naïve tendencies of contemporary anti-psychiatry. There is every reason to believe that accusatory thought is evidence, in those who practice it, of a propensity to the most summary of reactions. If knowledge can be considered the extension of the first human reactions to the stimuli and perils of the surrounding world, it can be reduced no further. To know the reaction, to evaluate the phenomenon in its relation with the word that designates it, is to no longer be content with the sole dispensing of reactive energies. ${ }^{4}$

\footnotetext{
s On the precautions to take in the evaluation of the influence of determinant factors cf. Cooper \& Shepherd (1970), Life change, stress and mental disorder: the ecological approach.

4 This study is the completed and considerably revised version of what appeared on the same subject in Confrontations psychiatriques (Starobinski, 1974).
} 


\section{REFERENCES}

Aquinas, T. Summa Theologica.

Aristotle. De Motu Animalium.

Balzac, H. de (1966). Adieu. In La comédie humaine (ed. du Seuil). Paris.

Bernard, C. (1865). Introduction à l'étude de la médecine expérimentale. Paris.

Bernheim, H.(1874). In Dictionnaire encyclopédique des sciences médicales (Dechambre) (3rd series). Paris.

Bichat, X. (1800). Recherches physiologiques sur la vie et la mort. Paris.

Biran, M. de (1954). Journal (3 vols.). (ed. Henri Gouhier). Neuchâtel.

Blaise, A. (1954). Dictionnaire latin-français des auteurs chrétiens. Strasbourg.

Bricheteau, I. (1827). In Encyclopédie méthodique, médecine. Agasse: Paris.

Brunot, F. (1967). Histoire de la langue française, des origines à 1900 . Paris.

Buffon, G. L. de (1836). Oeuvres completes. Duménil: Paris.

Cabanis, P.-J. G. (1802). Rapports du physique et du moral de l'homme. Paris.

Canguilhem, G. (1955). La formation du concept de réflexe. PUF: Paris.

Capuron, J. (1806). Nouveau dictionnaire de médecine, de chirurgie, de physique. Paris.

Castelli, B. (1746). Lexicon Medicum. Geneva. (First edition in Venice, 1607).

Chambers, E. (1743). Cyclopaedia (5th edn). London.

Champeynac (1610). Physique.

Claudel, P. (1907). Art poétique. Paris.

Constant, B. (1797). Des réactions politiques. Paris.

Cooper, B. \& Shepherd, M. (1970). Life change, stress and mental disorder: the ecological approach. In Modern Trends in Psychological Medicine (ed. J.-H. Price), pp. 102130.

Delpit, J. F. (1820). Dictionnaire des sciences médicales. Panckoucke: Paris.

Diderot, D. \& d'Alembert, J. L. (1751-1780). Encyclopédie (35 vols.). Paris.

Digby, K. (1644). Natural Bodies.

DuCange, C. (1743). Glossarium ad scriptores mediae et infimae latinitatis. Paris.

Ellenberger, H. F. (1970). Discovery of the Unconscious. Basic Books: New York.

Engels, F. (1878). Anti-Dühring. Leipzig.

Féraud, J.-F. (1788). Dictionnaire. Marseille.
Florkin, M. (1954). Médecine et médecins au pays de Lidge. Liège.

Freud, S. \& Breuer, J. (1895). Studien über Hysterie. Vienna. Goclenius, R. (1613). Lexicon philosophicum. Frankfurt.

Hanin, M.-L. (1811). Vocabulaire médical. Paris.

Heath, T. (1949). Mathematics in Aristotle. Oxford.

Huguet, E. (1965). Dictionnaire de la langue française du seizidme siècle, vol. 6. Paris.

James, R. (1743-1745). The Medical Dictionary (3 vols.). London.

Jaspers, K. (1948). Allgemeine Psychopathologie (5th edn). Berlin and Heidelberg.

Koyré, A. (1939). Etudes galiléennes. Paris.

Lewis, A. (1971). 'Endogenous' and 'Exogenous': a useful dichotomy? Psychological Medicine 1, 191-196.

Lewis, A. (1972). 'Psychogenic': a word and its mutations. Psychological Medicine 2, 209-215.

Lief, A. (1948). The Commonsense Psychiatry of Dr Adolf Meyer. New York, Toronto and London.

Littré, E. (1863-1877). Dictionnaire de la langue française. Paris.

Mach, E. (1902). Die Analyse der Emfindungen (3rd edn). Jena.

Montesquieu, Ch. L. de (1743). Considérations sur les causes de la grandeur des romains et de leur décadence. Paris.

Nysten, P.-H. (1814). Dictionnaire de médecine. Paris.

Oxford English Dictionary (1884-1928) (ed. J. A. H. Murray et al.). London.

Pomponazzi, P. (1525). De reactione. Venice.

Roger, J. (1963). Les sciences de la vie dans la pensée française du XVIII siecle. Paris.

Saussure, F. de (1916). Cours de linguistique générale. Geneva.

Schiff, M. (1894). Recueils des mémoires physiologiques. Lausanne.

Souter, A. (1949). A Glossary of Later Latin. Oxford.

Starobinski, J. (1970). Sur les fluides imaginaires. La relation critique, pp. 196-213. Paris.

Starobinski, J. (1974). Confrontations psychiatriques, pp. 1942. Paris.

Starobinski, J. (1975). La vie et les aventures du mot 'reaction'. Modern Language Review 70, n.4, pp. xxi-xxxi.

(Trévoux). Dictionnaire de Trévoux (5th edn, 1743).

Valéry, P. (1973). Cahiers (2 vols.). Paris.

Vossius, G.-J. (1695). De vitiis sermonis. In Aristarchus sive de Arte Grammatica. Amsterdam.

Wesley, J. (1872). Works.

Zabarella, J. (1589). De Rebus Naturalibus. Padova. 